\title{
Cytotoxic effects of S-(+)-Carvone on selected human cancer cell lines
}

\begin{abstract}
$S$-(+)-Carvone (S-CVN), the main constituent of Caraway seed (Carum carvi L.Umbelliferae), has been reported to show significant anticancer and chemopreventive effects against several cancer types. The current study aimed to evaluate the cytotoxic effects of $S$-CVN on four different human cancer cell lines: ovarian cancer (SW-626), triple negative breast cancer (BT-20), prostate cancer (PC-3) and lymphoma (RAJI). Using MTS proliferation assay, $S$-CVN showed significant concentration-dependent anti-proliferative effects against the chosen cancer cell lines, with $\mathrm{IC}_{50}$ values of $147,117,199$ and $228 \mu \mathrm{M}$ in SW-626, PC-3, BT-20 and RAJI, respectively. Mechanistically, $S$-CVN with its $\alpha, \beta-$ unsaturated carbonyl functionality has the potential to interact with cellular nucleophilic functional groups through Michael's addition type of reaction. The covalent interaction may explain the observed anti-proliferative activity. To further understand the mechanism of $S$-CVN cytotoxicity, glutathione (GSH and GSSG) were added to SW-626 cell line as pre- and co-treatments with $S$-CVN. According to results, the cell viability was enhanced and the cytotoxic effect of $S$-CVN was extremely decreased using a range of GSH/GSSG concentrations $(50-1000 \mu \mathrm{M})$. Moreover, the interaction between GSH and $S$-CVN was further confirmed by using thin layer chromatography (TLC). This is presumably attributed to the fact that the nucleophilic thiol function in GSH interacts with $S$-CVN , $\beta$-unsaturated ketone moiety at $\beta-\mathrm{C}$. The obtained data suggests that the reactivity of the electrophilic functionality of $S$-CVN plays a crucial role in its cytotoxicity.
\end{abstract}

Keywords: $S-(+)$-Carvone, cytotoxicity, breast cancer cells, ovary cancer cells, prostate cancer cells, lymphoma, glutathione, MTS assay, thin layer chromatography
Volume 8 Issue 4 - 2019

\section{Enas A Alasmari, Ahmed S Mehanna}

Department of Pharmaceutical Sciences, MCPHS University, United States

Correspondence: Ahmed S Mehanna, Department of Pharmaceutical Sciences, MCPHS University, Boston, MA, United States, Tel 617.732.2955, Email ahmed.mehanna@mcphs.edu

Received: July 23, 2019 | Published: July 30, 2019
Abbreviations: GSH, $\gamma$-L-Glutamyl-L-cysteinyl-glycine; GST, glutathione-S-transferase; ACF, aberrant crypt foci; DMEM, dulbecco's modified eagle medium; TLC, thin layer chromatography; Trx, thio-redoxin; Grx, gluta-redoxin

\section{Introduction}

Herbalism, one of the oldest systems of medicine humans have ever known, is the practice of making or prescribing plant-based herbal medicines. ${ }^{1}$ Over the past centuries, medicinal herbs were of great importance. Looking back in time, people were healthier and more competent against diseases compared to people at the present time. The reason behind this is thought to be partly due to the healthy diet and lifestyle they had which depends mainly on traditional herbal remedies and alternative medicine. It is worth mentioning that alternative and herbal medicine has also contributed significantly in the development of useful synthetic chemotherapeutic drugs. So far, the discovery of anticancer and chemotherapeutic treatments throughout the years has been successful, in terms of effectiveness and cancer remission. ${ }^{2}$ However, chemotherapeutic drugs are not devoid of serious toxic side effects. Due to the high toxicity associated with anticancer treatments, efforts have been directed toward the use of herbal medicines and anticancer products derived from plants. Currently, there are four classes of plant-based compounds that exhibit anticancer activity and they include: vinca alkaloids, taxanes, epipodophyllotoxins, and camptothecin derivatives. ${ }^{2}$ All of these plants have demonstrated significant inhibition on cancer growth. Furthermore, natural products still have enormous potential to provide promising chemo preventive and anticancer therapeutic compounds.

\section{S-(+)-Carvone from caraway plant}

S-(+)-Carvone or d-Carvone, (as shown in Figure 1 has a molecular formula of $\mathrm{C}_{10} \mathrm{H}_{14} \mathrm{O}$ with a molecular weight of $150.22 \mathrm{~g}$ / mole. Its density is $0.96 \mathrm{~g} / \mathrm{mL}$ at $25^{\circ} \mathrm{C}$ ), is a major monoterpenoid constituent found abundantly in the oil of caraway seed (Carum carvi L. Umbelliferae). ${ }^{3-6}$ In nature, carvone doesn't exist as racemic mixture, instead, it is known to be produced as pure enantiomers either $l$ - or $d$-isomer., $S$-(+)-Carvone found in caraway oil and thought to be the responsible component for the distinctive smell of caraway, while $R-(-)$-Carvone found in spearmint where it gives its minty aroma. Over the past couple years, $S-(+)$-Carvone has been studied widely and has been reported to have numerous biological uses, including, potato sprouting inhibition, ${ }^{5}$ antioxidant, ${ }^{8,9}$ antihyperglycemic, ${ }^{6}$ anticonvulsant,${ }^{10}$ antimicrobial, ${ }^{11}$ insecticidal,${ }^{4}$ and fungicidal properties. ${ }^{11}$

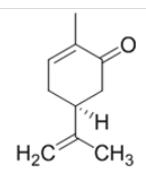

$S$-(+)-Carvone ((S)-5-Isopropenyl-2-methyl-2-cyclohexenone)

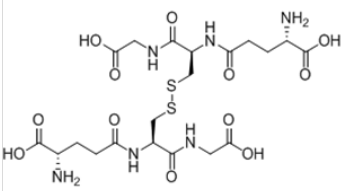

L-Glutathione Oxidized (GSSG)

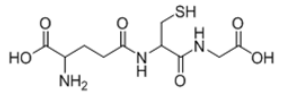

L- Glutathione Reduced (GSH)
Figure I List of tested compounds.

\section{S-(+)-Carvone and cancer}

Recently, monoterpenes from essential oils have been investigated because of their protective antioxidant effect that helps in reducing the damage caused by free radicals, which have been reported presumably 
to be one of main causes of cancer disease. ${ }^{12} S$-Carvone, a monoterpene ketone, has the ability to induce phase II detoxifying enzymes such as glutathione-S-transferase (GST), that has a chemopreventive action, because anticancer-related activities are associated with their capability to stimulate the activity of detoxifying enzymes. ${ }^{8,9}$

$S$-(+)-Carvone has been tested widely on various types of human and animal cancer cell lines and has exhibited significant results in regard to inhibition of cancer growth. For example, $S$-CVN's anti proliferative and anticancer potential was demonstrated on different human colon cancer cell lines (HT-29 and SW480). It was established that supplementation with $S$-CVN significantly inhibited cell viability by enhancing the collapse of the mitochondrial membrane potential. ${ }^{12}$ Furthermore, in-vivo studies were conducted recently which reported that supplementation of caraway or $S-C V N$ at $10 \mathrm{mg} / \mathrm{kg}$ body weight has chemopreventive activity against colon carcinogenesis that is induced by 1,2-dimethylhydrazine (DMH) and a considerable reduction in the incidence of polyps/aberrant crypt foci (ACF) by initiating a balanced oxidative/antioxidative effect. ${ }^{12-14}$ Previous investigations demonstrated that $S$-CVN exerted its potential chemopreventive effect by preventing initiation and stimulation of pro-carcinogen through interaction with the P450 1A1 system. ${ }^{2}$ It has also been established that nitrosamine-induced pulmonary adenoma and forestomach tumor formation are inhibited by $S$-CVN through its protective effect via the stimulation of enzymes in phase II especially glutathione-Stransferase activity. ${ }^{15}$ Another study reported that $S$-CVN might have a potential anticancer activity against brain tumor; the study was conducted using N2a neuroblastoma cell line. The results indicated that $S$-CVN at lower concentrations (at $25 \mathrm{mg} / \mathrm{L}$ ) may act as a cancer chemo-preventive agent by increasing the total antioxidant capacity levels. However, at higher concentrations $(100 \mathrm{mg} / \mathrm{L})$, it significantly increases the levels of oxidative stress by depleting GSH levels and, hence, reduction in cell growth. ${ }^{16}$

\section{Glutathione (GSH)}

$\gamma$-L-Glutamyl-L-cysteinyl-glycine, a ubiquitous tripeptide known as glutathione (GSH) (Figure 1), is a major antioxidant molecule that plays a key role in cellular defense. ${ }^{17-19}$ There are two forms of GSH: the reduced form that is found abundantly in almost all tissues with intracellular concentration ranges from $1 \mathrm{mM}$ to $10 \mathrm{mM}$, and the oxidized form (GSSG) (Figure 1) which comprises a small amount of the total glutathione. ${ }^{17,18} \mathrm{GSH}$ is a versatile molecule that is involved in numerous cellular processes, including the reduction of the disulfide moiety in oxidized glutathione (GSSG), protein S-glutathionylation to regulate signal transduction and enzyme activity, ${ }^{17,20}$ conjugation of electrophilic compounds, catabolic metabolites, and xenobiotic to facilitate their excretion. Furthermore, it has an important role in maintaining the stability of intracellular redox status by acting as a protective antioxidant, which scavenges ROS through the reduction and neutralization of free radicals and ROS with or without the presence of enzymatic catalysis. ${ }^{17-19}$ GSH exists primarily in its reduced form, which has a thiol $(-\mathrm{SH})$ group in its cysteine residue. This thiol group acts as a soft nucleophile to attack electrophilic species, inactivate their action by conjugation, and eventually enable their excretion. Consequently, GSH is considered the first line of defense in maintaining cell homeostasis. ${ }^{17,18,21}$

\section{Rationale of study and hypothesis}

The aim of this study is to evaluate the cytotoxic potential of $S$ $(+)$-carvone on several human cancer cell lines with advanced stage: triple negative breast cancer (BT-20), prostate cancer (PC-3), ovarian cancer (SW 626) and B-lymphoma (RAJI).

\section{Hypothesis}

Based on the reported activities and the structural features of $S$-(+)-carvone, we hypothesize that $S$-(+)-carvone will demonstrate cytotoxicity on the chosen human cancer cell lines: triple negative breast cancer (BT-20), prostate cancer (PC-3), ovarian cancer (SW 626) and B-lymphoma (RAJI) cells.

\section{Rationale behind the choice of S (+)-Carvone}

The exact mechanism of action for $S$-(+)-carvone in cell death induction still needs more investigations. ${ }^{12}$ However, based on the reported effects of $\alpha, \beta$-unsaturated ketone, which is known to interact covalently with any nucleophilic compounds through 1,4 Michael's addition reaction, ${ }^{22,23} S-\mathrm{CVN}$ as a monoterpene ketone carrying this electrophilic system (Michael's acceptor) has the potential to interact covalently with any cellular nucleophiles, such as sulfur-containing moiety in cellular proteins and glutathione (GSH). ${ }^{24}$ Thus, the Michael's adduct will be formed; as illustrated below in Schemes I, II \& III.

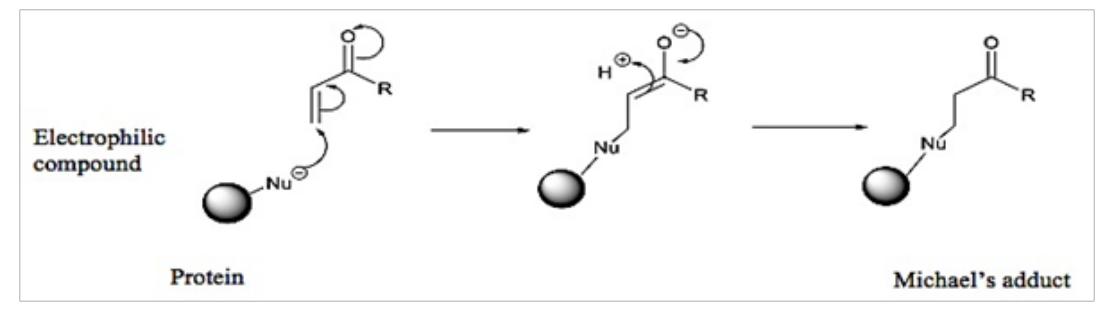

Scheme I An illustration of Michael's addition reaction of cellular nucleophile to an electrophilic compound.

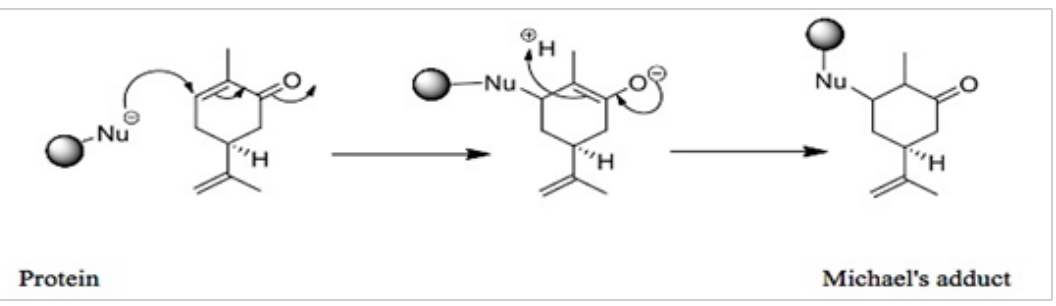

Scheme II An illustration of Michael's addition reaction of cellular nucleophile to S-(+)- carvone. 


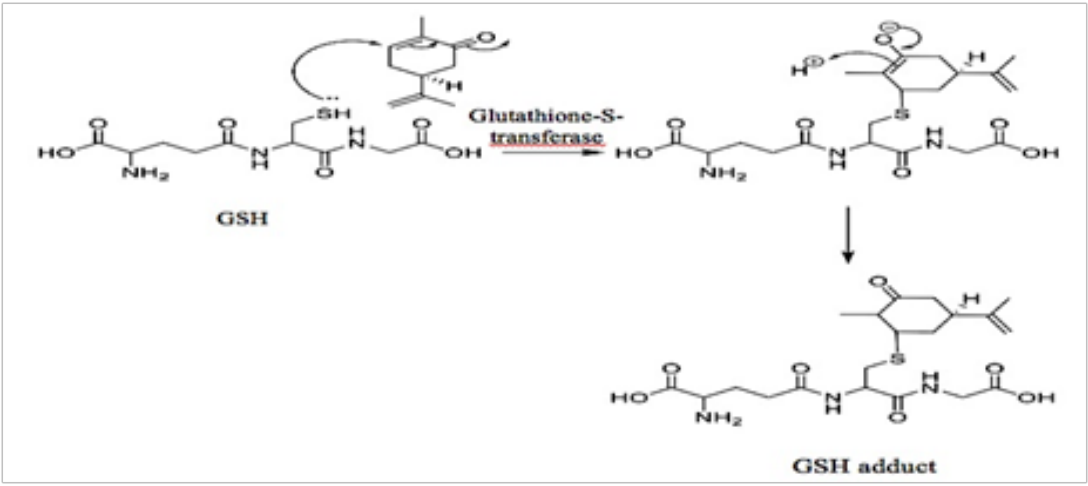

Scheme III Possible formation of GSH adduct of S-(+)-carvone.

One study has been conducted in mice using Carvone from dill and caraway oil to investigate its effect on the levels of detoxifying enzyme glutathione-S-transferase (GST). It was found that $S$-CVN as an electrophile has the ability to induce GST. Furthermore, it was shown that $\alpha, \beta$-unsaturated ketone is crucial for the induction of detoxifying enzyme GST as it may interact with the thiol function of GSH or GST through Michael's addition reaction and eventually get excreted ${ }^{25}$ As of that, glutathione (GSH and GSSG) were added to one type cell line SW-626 (on which $S$-CVN shows the most potency) as pre- and co-treatments with $S$-CVN to observe any possible protection from cellular toxicity caused by the compound.

\section{Materials and methods}

\section{Cancer cell lines}

All cancer cell lines (SW-626, PC-3, BT-20 and RAJI)) were purchased from ATCC (Manassas, VA, USA). ${ }^{26-29}$

\section{Chemicals}

$S$-(+)-carvone $(\geq 96 \%, \mathrm{FG})$, reduced and oxidized glutathione (GSH/GSSG) were purchased from Sigma-Aldrich (St. Louis MO, USA). Stock solutions $(100 \mathrm{mM})$ of the compounds were prepared in DMSO, and complete media for S-CVN and GSH compounds respectively. Fresh dilutions in media were prepared for the compounds before each experiment. No evidence of cytotoxicity of the solvent was observed at the maximum concentration used $(1.5 \%)$ as seen in Figure $2 \&$ Table 1.

Table I IC I0 $_{5}$ values of S-(+)-Carvone on four different cell lines

\begin{tabular}{lllll}
\hline Cell Line Type & SW-626 & PC-3 & BT-20 & RAJI \\
\hline IC50 & $147 \mathrm{mM}$ & $117 \mathrm{mM}$ & $199 \mathrm{mM}$ & $228 \mathrm{mM}$ \\
\hline
\end{tabular}

\section{Cell culture and treatment protocol}

The cells were cultured in Dulbecco's Modified Eagle Medium (DMEM) supplemented with $10 \%$ Fetal Bovine Serum (FBS) and $1 \%$ Penicillin-Streptomycin. Then, they were incubated at $37^{\circ} \mathrm{C}$ in a humidified atmosphere of $5 \% \mathrm{CO}_{2}$ until cell confluent rate reached $80-90 \%$. After that, all cells were seeded in 96 well plate with a density of 10,000 cells/200L/well in triplicates. Following treatment with different concentrations of $S$-CVN, the plates were incubated in a humid atmosphere with $5 \% \mathrm{CO}_{2}$ at $37^{\circ} \mathrm{C}$ for 48 hours. Then, the MTS reagent $(20 \mu \mathrm{L})$ was added to every well in the 96 well plate and then incubated for 180 minutes. Finally, the results were taken by reading the absorbance of the solution at $490 \mathrm{~nm}$ using MicroPlate reader.

\section{For glutathione tests}

To study any possible interactions between GSH, GSSG and $S$-CVN, combination tests were performed on ovarian cancer cells (SW626). A toxic dose of $S$-CVN $(200 \mu \mathrm{M})$ and different molar concentrations of GSH or GSSG were added to the cells for $24 \mathrm{hr}$ incubation. Alternately, a fixed dose of GSH and GSSG $(200 \mu \mathrm{M})$ used with range of concentrations of $S$-CVN. Then, they were added to the cells. Another procedure was performed where SW626 cells were pre-treated with different molar concentrations of GSH and GSSG for $24 \mathrm{hrs}$. Then, a toxic dose of $S$-CVN $(200 \mu \mathrm{M})$ was added to the wells following old media removal. After $24 \mathrm{hr}$ incubation period, MTS was added to the wells after removing the old media to avoid any unwanted interaction.

\section{Cell viability assay}

The cell viability was determined by a colorimetric assay called MTS Cell Proliferation Assay (Abcam, Cambridge, MA, USA).

\section{Thin layer chromatography (TLC)}

This method was performed on Agela TLC glass plates precoated with silica as stationary phase and $80 \%$ dichloromethane (DCM) $/ 20 \%$ hexane mixture was used as mobile phase. DCM solvent was used to solubilize $S$-CVN while GSH was first solubilzed in $10 \% \mathrm{NH} 4 \mathrm{OH} /$ methanol as polar solvent then $5 \%$ of this mixture was added to DCM solvent. For visualization, UV illumination at $254 / 365 \mathrm{~nm}$ was used.

\section{Statistical analysis}

All statistical analyses were performed using Graph Pad Prism (La Jolla, CA, USA). Data were reported as mean \pm SEM. The comparisons between multiple groups were performed using one-way analysis of variance (ANOVA). The results were considered statistically significant at $\mathrm{P}<0.05$. A post-hoc Dunnett's test was performed. Three independent experiments were performed for each result.

\section{Results}

The following are the results of MTS-proliferation assay:

a. The anti-proliferative effect of $S$-CVN compound on four different human cancer cell lines (SW-626, PC-3, BT-20 and RAJI). The compound toxicity was reported in terms of percentage of viable cells after incubating the treated cells for 48 hours.

b. The assay was also performed to determine the effect of DMSO on the cells as a control. 
c. Exogenous glutathione (GSH and GSSG) were added individually to SW626 cells for 24 hours as controls. Also, they were used with $S$-CVN as both pre- and co-treatments.

Thin layer chromatography (TLC) was used to identify and monitor the progress of any reactions could occur between $S$-CVN and GSH.

\section{Individual tests}

As depicted in Figure $2 \&$ Table 2, S-CVN caused statistically significant cytotoxicity at $100-500 \mu \mathrm{M}$ in $\mathrm{SW}-626,50-1000 \mu \mathrm{M}$ in
PC-3, $100-1000 \mu \mathrm{M}$ in BT-20 and $100-1500 \mu \mathrm{M}$ in RAJI after $48 \mathrm{hr}$ incubation. SW-626 cell viability reduced to almost $8 \%$. S-CVN shows $50 \%$ cell inhibition at $147 \mu \mathrm{M}\left(\mathrm{IC}_{50}\right)$ as seen in Table 3. In PC-3, cell viability decreased to almost $11 \%$ at $1 \mathrm{mM}$. $S$-CVN at $117 \mu \mathrm{M}$ inhibits cell viability by $50 \%$. In the aggressive type of breast cancer cell (BT$20)$, high concentration $(1 \mathrm{mM})$ was needed to reduce cell viability to almost $7 \% . \mathrm{IC}_{50}$ was detected at $199 \mu \mathrm{M}$ (Table 2). In lymphoma cell line (RAJI), cell viability decreased to almost $7 \%$ at $1.5 \mathrm{mM}$. $\mathrm{IC}_{50}$ was determined at $228 \mu \mathrm{M}$ as seen in Table 2. According to the obtained results, $S$-CVN caused antiproliferation in a concentration-dependent fashion in all selected cancer cell lines.

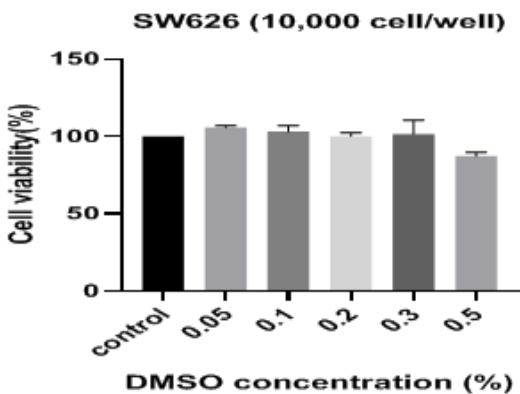

PC-3 (10,000 cell/well)

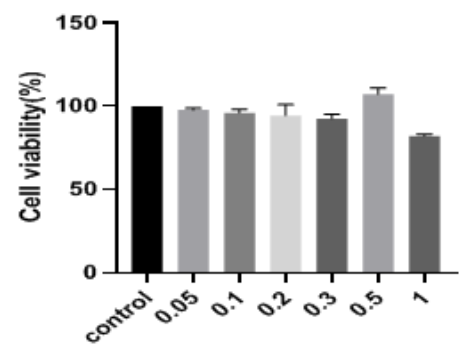

DMSO concentration $(\%)$

BT-20 (10,000 cell/well)

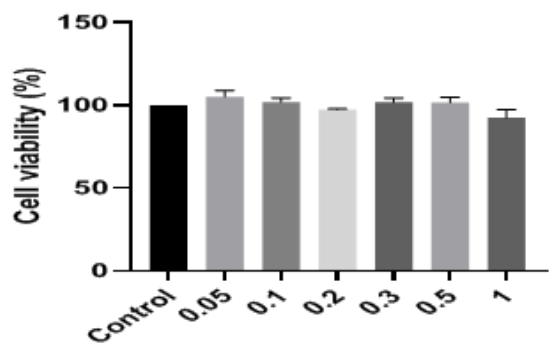

DMSO concentration $(\%)$

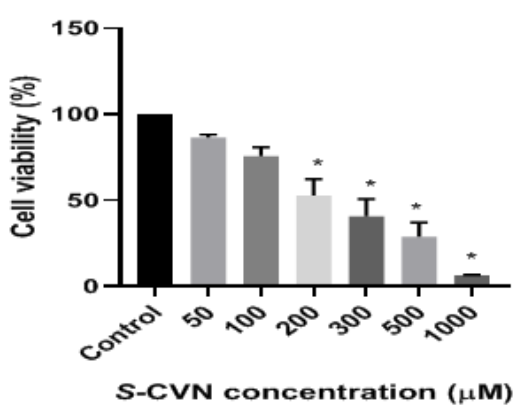

RAJI (10,000 cells/well)
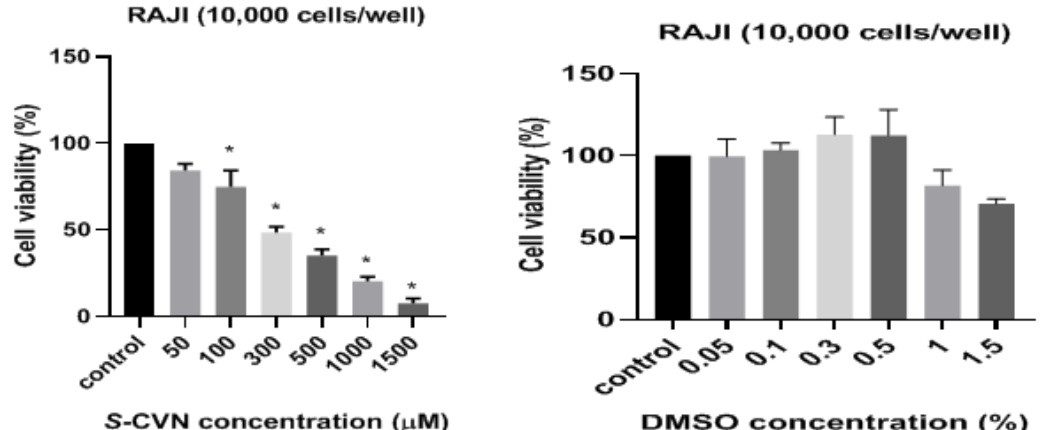

DMSO concentration (\%)

Figure 2 Effect of S-CVN and DMSO on cell viability of SW 626, PC-3, BT-20 and RAJl cell lines. Data are expressed as mean \pm SEM of three independent experiments. $* P$ - value $<0.05$ indicates significant difference with respect to control. 
Table 2 Effect of S-CVN and DMSO on cell viability of SW 626, PC-3, BT-20 and RAJl cell lines. Data are expressed as mean \pm SEM of three independent experiments

\begin{tabular}{lllllllll}
\hline S-CVN Concentration (mM) & Control (0) & $\mathbf{5 0}$ & $\mathbf{1 0 0}$ & $\mathbf{2 0 0}$ & $\mathbf{3 0 0}$ & $\mathbf{5 0 0}$ & $\mathbf{1 0 0 0}$ & $\mathbf{1 5 0 0}$ \\
\hline SW 626 & 100 & 86 & 65 & 48 & 32 & 8 & - & - \\
PC 3 & 100 & 78 & 63 & 39 & 29 & 19 & 11 & - \\
BT 20 & 100 & 87 & 76 & 53 & 41 & 26 & 7 & - \\
RAJl & 100 & 84 & 75 & - & 48 & 35 & 20 & 7 \\
\hline DMSO Concentration (\%) & Control (0) & $\mathbf{0 . 0 5}$ & $\mathbf{0 . 1}$ & $\mathbf{0 . 2}$ & $\mathbf{0 . 3}$ & $\mathbf{0 . 5}$ & $\mathbf{1}$ & $\mathbf{1 . 5}$ \\
\hline SW 626 & 100 & 106 & 103 & 100 & 102 & 87 & - & - \\
PC 3 & 100 & 98 & 96 & 94 & 93 & 107 & 82 & - \\
BT 20 & 100 & 105 & 102 & 97 & 102 & 102 & 92 & - \\
RAJl & 100 & 100 & 103 & - & 113 & 112 & 82 & 71 \\
\hline
\end{tabular}

\section{Glutathione tests on SW-626 cell line}

For GSH effects on SW-626 (Figure 3 \& Table 3), no cytotoxic effects were seen on cell viability at all concentrations $(50-1000 \mu \mathrm{M})$ as shown in Figure 3A. For the combination effects of a toxic dose of $S$-CVN $200 \mu \mathrm{M}$ with different concentrations of GSH from (50$1000 \mu \mathrm{M})$, no significant cytotoxicity was seen on cell viability at all mentioned concentrations after $24 \mathrm{hr}$ incubation Figure 3B. For GSH pretreatment effect in Figure 3C, there was no significant cytotoxicity observed on cell viability at all concentartions $(50-1000 \mu \mathrm{M})$. In
Figure 4 \& Table $4, S$-CVN effect was first tested alone for $24 \mathrm{hr}$. A statistically significant concentration-dependent cytotxicity was observed at $(200-500 \mu \mathrm{M})$ as compared to control group. While for the combination effects of a fixed dose of GSH $200 \mu \mathrm{M}$ and different concentrations of $S$-CVN mentioned above, no significant cytotoxicity was seen on cell viability even at the highest concentration $(500 \mu \mathrm{M})$ where cell viability reduced to only $82 \%$. Apparently, GSH disturbed the cytotoxic effects of $S$-CVN leading to its reduction. This is could be explained by the interaction of GSH nucleophilic thiol group and the electrophilic $\alpha, \beta$-unsaturated carbonyl of $S$-CVN.

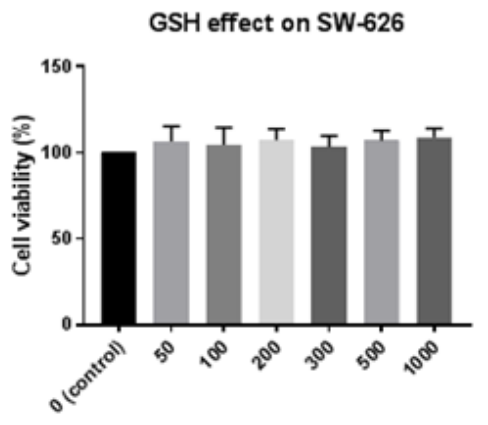

a)
GSH concentration $(\mu \mathrm{M})$

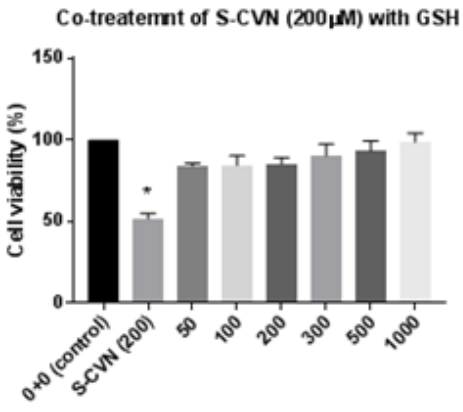

b)

GSH concentration ( $\boldsymbol{M}$ )

S.CVN effect on GSH-pretreated SW-626

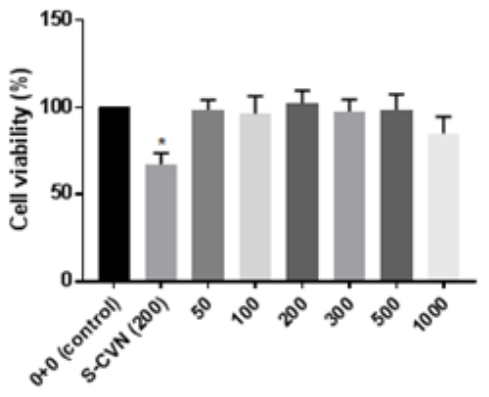

c)

GSH concentration $(\mu \mathrm{M})$

Figure 3 (A) Effect of GSH on cell viability of SW-626 cell line.

(B) Co-treatment effects of S-CVN $(200 \mu M)$ with GSH on cell viability of SW-626 cell line.

(C) S-CVN effect on cell viability of GSH-pretreated SW 626 cell line. ${ }^{*}$ - value $<0.05$ indicates significant difference with respect to control. 
Table 3 (a) Effect of GSH on cell viability of SW-626 cell line

(b) Co-treatment effect of S-CVN $(200 \mu \mathrm{M})$ with GSH on cell viability of SW626 cell line

(c) S-CVN effects on cell viability of GSH-pretreated SW 626 cell line. Data are expressed as mean \pm SEM of three independent experiments

\begin{tabular}{llll}
\hline Concentration $(\mathrm{mM})$ & \multicolumn{3}{c}{ Cell Viability (\%) } \\
\cline { 2 - 4 } & $(\mathrm{a})$ & $(\mathrm{b})$ & $(\mathrm{c})$ \\
\hline $0+0$ (control) & 100 & 100 & 100 \\
S-CVN 200 & - & 51.64 & 67.35 \\
50 & 106.7 & 84.08 & 98.4 \\
100 & 104.7 & 84.25 & 96.28 \\
200 & 107.3 & 85.03 & 102.3 \\
& & & \\
300 & 103.4 & 90.15 & 97.52 \\
500 & 107.1 & 92.98 & 98.5 \\
1000 & 108.8 & 98.61 & 85.01 \\
\hline
\end{tabular}

Table 4 Combination effects of GSH $(200 \mu M)$ and S-CVN on cell viability of SW626 cell line. Values represent the mean \pm SEM of three independent experiments

\begin{tabular}{lll}
$\begin{array}{l}\text { S-CVN concentration } \\
(\mathrm{mM})\end{array}$ & (S-CVN+GSH 200) & (S-CVN alone) \\
& Cell viability (\%) & Cell viability (\%) \\
\hline $0+0($ control) & 100 & 100 \\
GSH $200 \mu \mathrm{M}$ & 101 & - \\
50 & 90 & 84 \\
100 & 89 & 76 \\
200 & 88 & 60 \\
300 & 88 & 43 \\
500 & 82 & 19 \\
\hline
\end{tabular}

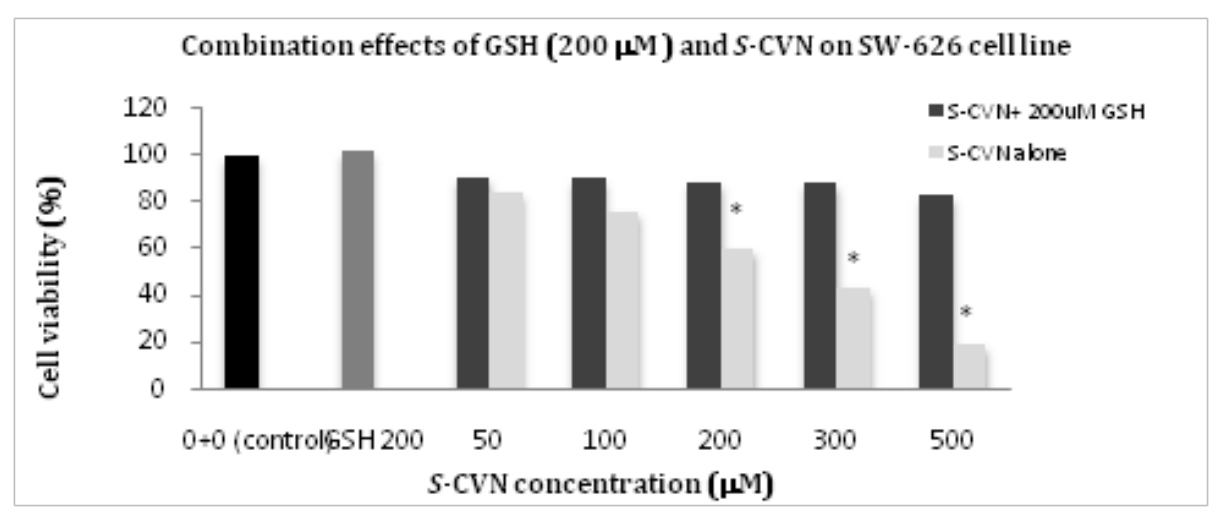

Figure 4 Combination effects of GSH $(200 \mu M)$ and S-CVN on cell viability of SW626 cell line. $* P$ - value $<0.05$, indicates significant difference with respect to $0+0$ (control).

For GSSG alone, no significant effect on cell viability was obsereved at all used concentrations $(50-1000 \mu \mathrm{M})$ after $24 \mathrm{~h}$ as well (Figure $5 \&$ Table 5). For the combination effects of a toxic dose of $S$-CVN $200 \mu \mathrm{M}$ with different concentrations of GSSG at (50$1000 \mu \mathrm{M})$ as represented in Figure $5 \mathrm{~A} \& 5 \mathrm{~B}$, there was no significant cytotoxicity seen on cell viability at all mentioned concentrations. For GSSG pretreatment effect, there was no significant cytotoxicity observed on cell viability as well at all concentartions $(50-1000 \mu \mathrm{M})$. At GSSG $500-1000 \mu \mathrm{M}$, cell viability started to decrease nonsignificantly Figure 5C. In Figure $6 \&$ Table 6, S-CVN was incubated alone in SW-626 for $24 \mathrm{hrs}$ as a control. A statistically significant cytotxicity was obsered at $200 \mu \mathrm{M}$ up to $500 \mathrm{M}$ as compared to control group. Then a combination regimen of a fixed dose of GSSG $200 \mu \mathrm{M}$ and different concentrations of $S$-CVN $(50-500 \mu \mathrm{M})$ was added to the cells. After $24 \mathrm{hr}$ incubation, no significant cytotoxicity was seen on cell viability even at the highest concentration mentioned above where cell viability reduced to only $87 \%$. This reduction in $S$-CVN cytotoxic effect could be due to the possible interaction of reduced GSH, after GSSG reduction, with $S$-CVN or the direct interaction of S atom in GSSG disulfide with $S$-CVN. According to the results of preand co-treatmens, the effect of $S$-CVN was almost abolished by the addition of GSH and GSSG. This is could be attributed to the possible protective effect of glutathione that is explained by the interaction with the electrophilic part of $S-C V N$.
Table 5 (a) Effect of GSSG on cell viability of SW-626 cell line

(b) Co-treatment effect of S-CVN $(200 \mu \mathrm{M})$ with GSSG on cell viability of SW-626 cell line

(c) S-CVN effects on cell viability of GSSG-pretreated SW 626 cell line. Data are expressed as mean $\pm \mathrm{SEM}$ of three independent experiments

\begin{tabular}{llll}
\hline Concentration (mM) & \multicolumn{3}{c}{ Cell Viability (\%) } \\
\cline { 2 - 4 } & $(\mathrm{a})$ & ( b ) & ( c ) \\
\hline $0+0$ (control) & 100 & 100 & 100 \\
S-CVN 200 & - & 54.21 & 58.73 \\
50 & 93.69 & 100.1 & 103.6 \\
100 & 95.73 & 103.5 & 104 \\
200 & 93.07 & 100.8 & 101.8 \\
300 & 94.28 & 97.73 & 101.5 \\
500 & 97.88 & 97.11 & 86.08 \\
1000 & 96.68 & 93.71 & 79.47 \\
\hline
\end{tabular}


a)

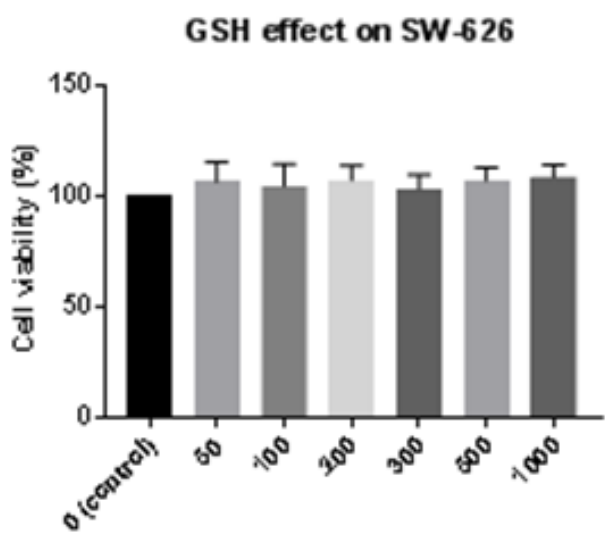

GSH concertration ( $\mu$ M)

b)

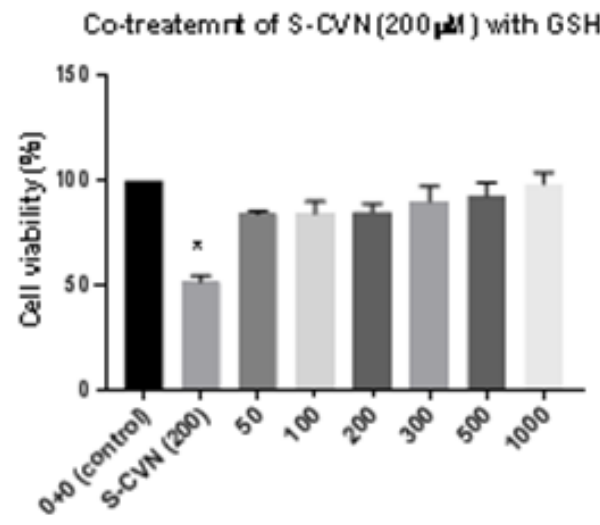

GSH concertration ( 2 الم)

S.CVN effect on GSH-pretrezed SW-626

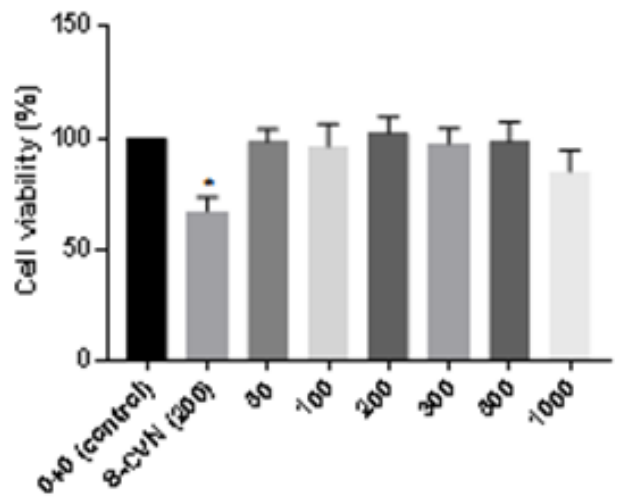

c)

GSH concentration ( $\mu$ M)

Figure 5 (A) Effect of GSSG on cell viability of SW-626 cell line.

(B) Co-treatment effect of S-CVN $(200 \mu \mathrm{M})$ with GSSG on cell viability of SW-626 cell line.

(C) S-CVN $(200 \mu \mathrm{M})$ effects on cell viability of GSSG-pretreated SW 626 cell line. *P- value $<0.05$ indicates significant difference with respect to control

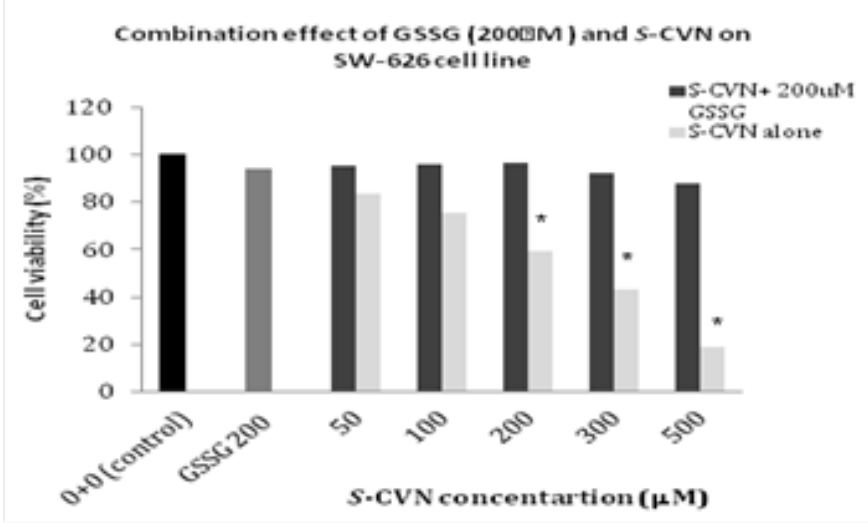

Figure 6 Combination effects of GSSG $(200 \mu \mathrm{M})$ and S-CVN on cell viability of SW626 cell line. Values represent the mean \pm SEM of three independent experiments. $* P$ - value $<0.05$, indicates significant difference with respect to $0+0$ (control)
Table 6 Combination effects of GSSG $(200 \mu \mathrm{M})$ and S-CVN on cell viability of SW626 cell line. Values represent the mean士SEM of three independent experiments

\begin{tabular}{lll}
\hline GSSG concentration (mM) & $\begin{array}{l}\text { S-CVN+GSSG } \\
\text { Cell viability (\%) }\end{array}$ & $\begin{array}{l}\text { S-CVN alone } \\
\text { Cell viability (\%) }\end{array}$ \\
\hline $0+0$ (control) & 100 & 100 \\
GSSG 200mM & 94 & - \\
50 & 95 & 84 \\
100 & 96 & 76 \\
200 & 96 & 60 \\
300 & 92 & 43 \\
500 & 88 & 19 \\
\hline
\end{tabular}




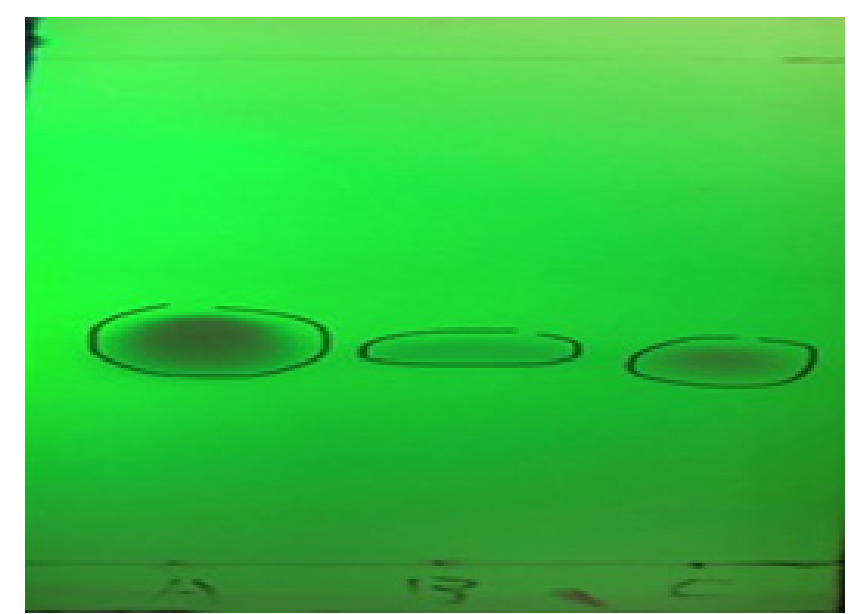

Figure 7 Thin layer chromatography (TLC) of S-CVN (A), GSH (B) and $\mathrm{S}-\mathrm{CVN}$ and GSH (C). Mobile phase is $80 \%$ dichloromethane (DCM) and $20 \%$ hexane. Stationary phase is silica gel.

\section{Thin layer chromatograpghy (TLC)}

To further examine any possible interaction betweein GSH and $S$-CVN, a thin layer chromatography (TLC) was employed. As seen in TLC sheet (Figure 7), where mobile phase is drawn up the plate, $S$-CVN (spot A) as a relatively non-polar compound showing a dark spot with good intesity ascended the TLC plate. However, for GSH as a polar compound with non-congujated system showed very faint spot under the UV light (spot B) moving up the plate a bit slower than $S$-CVN. For C, only one spot with intermediate intesnity can be observed indicating a possible reaction between GSH and $S$-CVN.

\section{Discussion}

The aim of this study was to assess any cytotoxic potential that $S$-(+)-carvone (Figure 1) might show on selected human cancer cell lines: ovarian cancer (SW-626), prostate cancer (PC-3), triple negative breast cancer (BT-20) and lymphoma (RAJI). In this present study, the cells were treated with a range of molar concentrations $(50-1500 \mu \mathrm{M})$ in $96-w e l l$ plates, and incubated at $37^{\circ} \mathrm{C}$ in $5 \% \mathrm{CO}_{2}$ atmosphere for $48 \mathrm{~h}$. The viability of the treated cells was determined by MTS proliferation assay as a percentage relative to the cells in media control wells.

The results of the current research indicated that $S$-CVN exerted its cytotoxic effect in a concentration-dependent manner on all employed cell lines. The cytotoxicity of $S$-CVN was determined individually on all cell lines after $48 \mathrm{hr}$ incubation. It was found that $S$-CVN is inhibiting cell viability with $\mathrm{IC}_{50}$ values of $147,117,199$ and $228 \mu \mathrm{M}$ in SW-626, PC-3, BT-20 and RAJI, respectively (Table 1). The high concentrations used for $S$-CVN $(500-1500 \mu \mathrm{M})$ caused significant cytotoxicity on all selected cell lines (Figure $2 \&$ Table 2). Based on these compelling data obtained from in-vitro studies, $S$-CVN, as a natural product, could be a promising anticancer agent especially in the aggressive types of cancer like triple negative breast cancer, lymphoma and metastatic ovarian and prostate cancer.

Since $S$-CVN is $\alpha, \beta$-unsaturated carbonyl compound and have the potential to act as an electrophile, it could be responsible in part of its observed cytotoxicity. This attractive electrophilic system could be toxic to both GSH, leading to its depletion ${ }^{16}$, and to other cellular protein nucleophiles, leading to cell death, due to the possible formation of Michael's adduct through 1,4 addition reaction. ${ }^{23,24}$
This suggestion was also proposed in one study, in which $S$-CVN, among a group of tested compounds, was the only compound to show a significant induction of glutathione-S-transferase enzyme system in all used cancer cells. This effect could be attributed to the electrophilic functionality of $\alpha, \beta$-unsaturated ketone system. According to the reported structure-activity relationship, $S$-CVN could potentially interact covalently with GST or GSH through 1,4 addition. ${ }^{25}$ Compounds with $\alpha, \beta$-unsaturated carbonyl system, also known as Michael acceptor, has the ability to interact covalently with cellular thiol-containing molecules, such as GSH. ${ }^{30}$ As of that, we investigated the effect of glutathione, as a nucleophile carrier, on $S$-CVN toxicity.

Reduced GSH was used as pre- and co-treatments with $S$-CVN on SW-626 cell line (on which $S$-CVN showed the highest cell toxicity effects among the selected cancer cell lines) for $24 \mathrm{~h}$-incubation. As stated in the results (Figure $3 \&$ Table 3 ), the viability of the cells was enhanced by the addition of different concentrations of GSH (50$1000 \mu \mathrm{M})$ before and with $S$-CVN $(200 \mu \mathrm{M})$ addition. Moreover, the toxicity of $S$-CVN was significantly decreased with GSH $200 \mu \mathrm{M}$ even at the highest concentration used $(500 \mu \mathrm{M})$ (Figure $4 \&$ Table 4$)$. These findings led to the proposal that this reduction in $S$-CVN cytotoxicity is caused by the reaction between $\alpha, \beta$-unsaturated carbonyl system of $S$-CVN and the nucleophilic thiol group in GSH.

Furthermore, the effect of $S$-CVN $(200 \mu \mathrm{M})$ was reduced even at the lowest concentrations of GSH $(50-100 \mu \mathrm{M})$ (Figure 3 \& Table $3)$. These results are explained by glutathione levels in cancer cells, which are considered high in general. This elevation of GSH levels is a protective and proliferative response for cell survival. ${ }^{17,31}$ For instance, one study indicated that the level of GSH in ovarian cancer cells can reach $126 \mathrm{nmol} / \mathrm{mg}$-protein, which is considered statistically significant compared to GSH levels in normal ovarian tissue that could increase to about $50 \mathrm{nmol} / \mathrm{mg}$-protein. ${ }^{31}$ As of that, this existed concentration of GSH could be partially responsible in the reduction of $S$-CVN's effect. To further examine whether GSH interacts with $S$-CVN, thin layer chromatography (TLC) was used, where $S$-CVN Figure $3 \mathrm{~A}$ as non-polar compound, with the dark spot, ascended in TLC plate a bit faster than the polar compound GSH Figure 3B. As shown in Figure 7, one spot with medium intensity can be spotted in $\mathrm{C}$ path ascending along with spots $\mathrm{A}$ and $\mathrm{B}$. This finding demonstrated the covalent interaction between GSH and $S$-CVN and possible formation of Michael's adduct.

For oxidized GSSG that was used as a pretreatment and a combination with $S$-CVN using different concentrations (50$1000 \mu \mathrm{M}$ ) for $24 \mathrm{~h}$ incubation; it showed almost the same results as of GSH, where $S$-CVN cytotoxic effects were almost prevented (Figure $5 \&$ Table 5). The fact that $S$-CVN cytotoxicity can be abolished by oxidized glutathione addition raises the question of how GSSG is affecting $S$-CVN activity. The explanation for that, is either due to the uptake of GSSG by the cells, followed by the conversion of GSSG to GSH by glutathione reductase enzyme, using NADPH as an electron donor, ${ }^{17-19,32}$ or by the direct interaction of disulfide $\mathrm{S}$ atom in GSSG with an active thiol group in cellular protein to form protein-S-SG and release one molecule of GSH that would eventually react with the electrophilic compound. The reaction of GSSG with protein is proceeded as: ${ }^{17}$

$$
\text { Protein }-S S G+G S H \rightleftarrows \text { Protein }-S H+G S S G
$$

This reaction of thiol-disulfied exchange runs at equilibrium depending on the concentration of GSH and GSSG inside the cells. ${ }^{17}$ 
In addition, there are an alternative cellular reduction systems that help reducing oxidized GSSG, such as, thio-redoxin(Trx), and gluta-redoxin(Grx) as indicated in Casagrande et al. ${ }^{32}$ when they demonstrated the glutathionylation of Trx by oxidized GSSG after its reduction. ${ }^{32}$ Furthermore, a recent study confirmed the reduction of disulfide molecules including GSSG by mammalian glutaredoxin 2 using thioredoxin reductase. Moreover, they studied the reduction reactions of extracellular GSSG inside the yeast Saccharomyces cerevisiae and how glutathione redox homeostasis is maintained. ${ }^{33-35}$ Another possible explanation is that GSSG disulfide itself could be involved directly in the reaction with $S$-CVN.

\section{Conclusion}

$S$-(+)-Carvone $(S-\mathrm{CVN})$, the major mono terpenoid in caraway seed, has been shown to have chemopreventive and anticancer effects on different cancer cell lines. In this present study, further screening was needed to test the compound on a variety of cancer cell lines, such as, ovarian cancer (SW-626), triple negative breast cancer (BT20 ), prostate cancer (PC-3) and lymphoma (RAJI). It was shown that $S$-CVN has significant cytotoxic effects on the chosen cancer cell lines.

The ovarian cell line SW-626 was treated with glutathione as pretreatment and combination regimens with $S$-CVN in an attempt to predict the mechanism by which this compound exerts its cytotoxic effects. According to the results obtained, glutathione enhanced the cell viability and prevented the cytotoxic effects of $S$-CVN. This can be attributed to the possible interaction of $S$-CVN with GSH in the cells by direct conjugation with the thiol group. Additionally, the interaction between GSH and $S$-CVN was further confirmed using thin layer chromatography (TLC).

According to the current results, $S$-CVN represents a potential therapeutic agent in cancer. Further investigation is needed to study the cytotoxic mechanisms of $S$-CVN on the selected human cancer cell lines and its effect on the key cellular signaling pathways, and the expression of transcription factors involved in its cytotoxicity effects.

\section{Acknowledgments}

None

\section{Conflicts of interest}

The author declares that there is no conflict of interest.

\section{References}

1. Ancient Egyptian Medicine. 2018.

2. Desa AG, Qazi GN, Ganju RK, et al. Medicinal plants and cancer chemoprevention. Current Drug Metabolism. 2008;9(7):581-591.

3. D-Carvone W224928. 2018.

4. Gonçalves JC, Alves AD, Araújo AE, et al. Distinct effects of carvone analogues on the isolated nerve of rats. European Journal of Pharmacology. 2010;645(1-3):108-112.

5. Hartmans KJ, Diepenhorst P, Bakker W, et al. The Use of Carvone in Agriculture: Sprout Suppression of Potatoes and Antifungal Activity Against Potato Tuber and Other Plant Diseases. Industrial Crops and Products. 1995;4(1):3-13.

6. Eddouks M, Lemhadri A, Michel J. Caraway and Caper: Potential Antihyperglycaemic Plants in Diabetic Rats. Journal of Ethnopharmacology. 2004;94(1):143-148.
7. Matsumura T, Ishikawa T, Kitajima J. Water-Soluble Constituents of Caraway: Carvone Derivatives and their Glucosides. Chemical and Pharmaceutical Bulletin. 2002;50(1):66-72.

8. Decarvalho C, Dafonseca M. Carvone: Why and How Should One Bother to Produce this Terpene. Food Chemistry. 2006;95(3):413-422.

9. Bicas J, Neri-Numa I, Ruiz A, et al. Evaluation of the Antioxidant and Antiproliferative Potential of Bioflavors. Food and Chemical Toxicology. 2011;49(7):1610-1615

10. Sousa DP, Nóbrega FF, Almeida RN. Influence of the Chirality of (R)$(-)$ - and (S)- (+)-carvone in the Central Nervous System: A Comparative Study. Chirality. 2007;19(4):264-268.

11. Janssen M, Luijendijk T, Scheffer J, et al. Antibacterial and Antifungal Activities of Caraway Oil. Landenberghaus Greifensee. Abstracts 19th International Symposium on Essential Oils and Other Natural Substances. 1988.

12. Vinothkumar R, Nalini N. Supplementation with d-Carvone Induces Cytotoxicity and Mitochondrial Mediated Apoptosis in Human Colon Cancer Cell Lines HT-29 and SW480. Internatinal Journal of Pharmaceutical and Biological Archives. 2013;4(2):502-510.

13. Vinothkumar R, Sudha M, Viswanathan P, et al. Modulating Effect of d-Carvone on 1,2-Dimethylhydrazine-Induced Pre-Neoplastic Lesions, Oxidative Stress and Biotransforming Enzymes, in an Experimental Model of Rat Colon Carcinogenesis. Cell Proliferation. 2013;46(6):705720 .

14. Kamaleeswari M, Deeptha K, Sengottuvelan M, et al. Effect of Dietary Caraway (Carum carvi L.) on Aberrant Crypt Foci Development, Fecal Steroids, and Intestinal Alkaline Phosphatase Activities in 1,2-Dimethylhydrazine-Induced Colon Carcinogenesis. Toxicology and Applied Pharmacology. 2006;214(3):290-296.

15. Wattenberg L, Sparnins V, Barany G. Inhibition of N-Nitrosodiethylamine Carcinogenesis in Mice by Naturally Occurring Organosulfur Compounds and Monoterpenes. Cancer Research. 1989;49(10):2689-2692.

16. Aydın E, Türkez H, Keleş MS. Potential Anticancer Activity of Carvone in N2a Neuroblastoma Cell Line. Toxicology and Industrial Health. 2013;31(8):764-772

17. Traverso N, Ricciarelli R, Nitti M, et al. Role of Glutathione in Cancer Progression and Chemoresistance. Oxidative Medicine and Cellular Longevity. 2013:1-10.

18. Pastore A, Federici G, Bertini E, et al. Analysis of Glutathione: Implication in Redox and Detoxification. Clinica Chimica Acta. 2003;333(1):19-39.

19. Brosnan J, Brosnan M. Sulfur-Containing Amino Acids: An Overview. The Journal of Nutrition. 2006;136(6):1636-1640.

20. Dalle-Donne I, Rossi R, Giustarini D, et al. S-glutathionylation in protein redox regulation. Free Radical Biology and Medicine. 2007;43(6):883898.

21. Huseby N, Sundkvist E, Svineng G. Glutathione and Sulfur Containing Amino Acids: Antioxidant and Conjugation Activities. Glutathione and Sulfur Amino Acids in Human Health and Disease. 2009:91-120.

22. Amslinger S. The Tunable Functionality of $\alpha, \beta$-Unsaturated Carbonyl Compounds Enables Their Differential Application in Biological Systems. Chem Med Chem. 2010;5(3):351-356.

23. Redeby T, Nilsson U, Altamore TM, et al. Specific Adducts Formed through a Radical Reaction between Peptides and Contact Allergenic Hydroperoxides. Chemical Research in Toxicology. 2010;23(1):203-210.

24. Nilsson A, Gäfvert E, Salvador L, et al. Mechanism of The Antigen Formation of Carvone and Related $\alpha, \beta$-Unsaturated Ketones. Contact Dermatitis. 2001;44(6):347-356. 
25. Zheng G, Kenney P, Lam L. Anethofuran, Carvone, and Limonene: Potential Cancer Chemoprotective Agents from Dill Weed Oil and Caraway Oil. Planta Medica. 1992;58(4):338-341.

26. SW 626 (ATCC® HTB-78 ${ }^{\mathrm{TM}}$ ). 2018.

27. PC-3 (ATCC® CRL-1435'TM). 2018.

28. ВT-20 (АТСС® НТВ-19тм). 2018.

29. Raji (ATCC® CCL-86 ${ }^{\mathrm{TM}}$ ). 2018.

30. Janzowski C. $\alpha, \beta$-Unsaturated Carbonyl Compounds: Induction of Oxidative DNA Damage in Mammalian Cells. Mutagenesis. 2003;18(5):465-470.

31. Gamcsik MP, Kasibhatla MS, Teeter SD, et al. Glutathione Levels in Human Tumors. Biomarkers. 2012;17(8):671-691.
32. Casagrande S, Bonetto V, Fratelli M, et al. Glutathionylation of Human Thioredoxin: A Possible Crosstalk Between the Glutathione and Thioredoxin Systems. Proceedings of the National Academy of Sciences. 2002;99(15):9745-9749.

33. Tan S, Greetham D, Raeth S, et al. The Thioredoxin-Thioredoxin Reductase System Can Function in Vivo as An Alternative System to Reduce Oxidized Glutathione in Saccharomyces Cerevisiae. Journal of Biological Chemistry. 2009;285(9):6118-6126.

34. Morgan B, Ezerina D, Amoako TN, et al. Multiple Glutathione Disulfide Removal Pathways Mediate Cytosolic Redox Homeostasis. Nature Chemical Biology. 2012;9(2):119-125.

35. Johansson C, Lillig CH, Holmgren A. Human Mitochondrial Glutaredoxin Reduces S-Glutathionylated Proteins with High Affinity Accepting Electrons from Either Glutathione or Thioredoxin Reductase. Journal of Biological Chemistry. 2003;279(9):7537-7543. 